Asian-Australasian Journal of

Food Safety and Security

ISSN 2523-1073 (Print) 2523-2983 (Online)

www.ebupress.com/journal/aajfss

\title{
Article \\ Qualitative analysis of insecticide residue in cauliflower samples collected from different regions of Bangladesh
}

\author{
Md. Sultan Ahmed ${ }^{1 *}$, Md. Mohsin Ali Sardar ${ }^{2}$, Masum Ahmad ${ }^{2}$ and Kamal Humayun Kabir ${ }^{1}$ \\ ${ }^{1}$ Division of Entomology, Bangladesh Agricultural Research Institute, Joydebpur, Gazipur-1701, Bangladesh \\ ${ }^{2}$ Department of Entomology, Bangladesh Agricultural University, Mymensingh, Bangladesh
}

*Corresponding author: Md. Sultan Ahmed, Division of Entomology, Bangladesh Agricultural Research Institute, Joydebpur, Gazipur-1701, Bangladesh. E-mail: sultan_palbari@yahoo.com

Received: 07 May 2018/Accepted: 27 May 2018/ Published: 31 May 2018

\begin{abstract}
The samples of the cauliflowers were analyzed to assess the residue level of six insecticides (i.e.; cypermethrin, quinalphos, diazinon, malathion, fenitrothion and acephate) using GC-FTD and GC-ECD method. Out of analyzed 75 collected samples of cauliflower from farmer's field of Jessore, Gazipur and Rangpur, $38.67 \%$ (29 from 75) were found to be contaminated with the insecticides. Many samples contained cypermethrin, acephate and fenitrothion residues. Quinalphos, acephate and fenitrothion were found as multiple product residues representing $13.79 \%$ (4 from 29) of the total contaminated samples and the rest $86.21 \%$ contained single insecticide residue. About 13.33\% (10 of 75) of the total samples had residues exceeding the MRL (Maximum Residue Limit) irrespective of single or multiple insecticide residues. Malathion residue was found only in one sample from Jessore. Two samples showed diazinon residue one from Jessore and the other one from Rangpur location. The detected residue levels of both malathion and diazinon were below the MRL, which might be due to higher rate of degradation. The presence of highest residue levels of insecticides in cauliflowers may be due to its irrational and repeated use before harvest.
\end{abstract}

Keywords: insecticide; residue; MRL; cauliflower

\section{Introduction}

Cauliflower is a cole crop which is vulnerable to the attack of many species of insect pests in its various stages (seedling, vegetative and mature stages) of the crop (Riley and Sparks, 2008). Out of them, diamond back moth and aphid are the main and most destructive pests in Bangladesh. The commercial farmers use a large quantity of insecticides to control these pests (Anon. 2001). The chemical means are vital and provide a rapid, costcompetitive and typically effective pest management tool (MacIntyre et al. 1989). Due to the lack of knowledge and non-availability of sustainable alternatives to pesticide, farmers of Bangladesh become dependent on pesticide for crop production. It was found that farmers used 71 different kinds of insecticides in vegetables at an alarming frequency an average of 11 times on cauliflower in Jessore, 8 times in Rangpur and 10 times in Gazipur in a cropping season (Anon. 2001). It was also found that many farmers sprayed insecticides every or every alternate day on cauliflower. A considerable number of farmers of those regions sell cauliflower without looking at withholding period of insecticidal spray or at an interval of 0-2 days after spray (Anon. 2001; Ahmed et al. 2005). These irrational and abuse of persistent insecticides has been responsible for widespread contamination of our environment i.e., soil, water, air and food (Finney, 1990). Insecticide residue in food has become a consumer's safety issue and the consumers have the right to know how much insecticide get incorporated in the food they eat. The present study is therefore, undertaken to quantify the insecticide residue in environmental cauliflower samples. 
2. Materials and Methods

The study was undertaken in the pesticide analytical laboratory, Bangladesh Agricultural Research Institute, Joydebpur, Gazipur during 2008-2009 seasons. Many types of chemicals were used in the analysis of the insecticides. All the chemicals (acetone, n-hexane, cyclohexane, methanol, acetonitrile, silicagel 60, sodium sulphate) and insecticide standards (quinalphos, diazinon, malathion, fenitrothion, acephate, cypermethrin) were procured from Sigma-Aldrich Laborchemikalien, Gmbh P. O. Box-100262, D-30918, Seelze, Germany via Bangladesh Scientific Pvt. Ltd. Dhaka, Bangladesh. Standards of insecticides contained 99.6\% purity.

\subsection{Collection of cauliflower samples from farmers field}

A total of seventy five samples of cauliflower were collected from farmer's field of three different locations such as Jessore, Gazipur and Rangpur. In selecting fields, standing crops and marketable size of cauliflower at harvest were the main criteria and samples were collected according to regulation made in the "Guidelines for the control of pesticide residues in foods" (Anon. 1996), which incorporate the EU directive (Anon.1979) and Codex recommendations (Anon.1993) regarding sampling. The size of the sample of cauliflower was $1 \mathrm{~kg}$. Field collected samples were kept in "Chilled box" and carried to the laboratory at the quickest time and preserved in refrigerator.

2.2. Extraction, separation and clean up of cauliflower samples

Collected samples $(250 \mathrm{~g})$ were chopped by knife on white board and mixed well. A sub sample of $20 \mathrm{~g}$ was taken into a wide mouth jar then $100 \mathrm{ml}$ of hexane was added to it. Sodium Sulphate $\left(\mathrm{Na}_{2} \mathrm{SO}_{4}\right)$ was also added with sample until water was removed from the sample. The mixture was then macerated with high-speed homogenizer (Ultra-turrax, IKA T18 basic, Germany) for 2 minutes. The homogenized material was then poured into $250 \mathrm{ml}$ conical flask and placed into the shaker (Refrigerated Shaker, Rexmed, Sweden) for $12 \mathrm{hrs}$ continuous shaking. After shaking, the slurry was filtered through whatman filter paper no.40 and a Buchner funnels with suction. The flask and filter cakes were rinsed with $25 \mathrm{ml}$ of hexane each. The filtrate was then transferred into $250 \mathrm{ml}$ round bottom flask and was dried to around 5-7 $\mathrm{ml}$ by evaporation using a rotary vacuum evaporator (Laborota-4001, Heidolph, Germany). Then, the concentrate filtrate was collected in a centrifuge tube adjusted at $10 \mathrm{ml}$ volume which was then centrifuged at $16500 \mathrm{rpm}$ for 10 minutes with Laboratory Refrigerated Centrifuges, Sigma-3K30, Germany. After centrifuge, supernatant was collected and cleaned up by Super Phase Extraction (SPE) cartridge. Then the final volume was kept in $10 \mathrm{ml}$ volumetric flask. Before injection, this volume was again cleaned up by High Performance Liquid Chromatography filter (0.2 PTFE) which was ready for injection.

\subsection{Detection and quantification of insecticide residue in cauliflower samples}

The condensed extracts were subjected to analysis by GC-2010 (Shimadzu). Flame Thirmionic Detector (FTD) was used for the detection of quinalphos, diazinon, malathion, fenitrothion and acephate and Electron Capture Detector (ECD) for cypermethrin. The capillary column used in FTD was ATTM-1, $30 \mathrm{~m}$ in length, $0.25 \mathrm{~mm}$ inner diameter (ID) and $0.25 \mu \mathrm{m}$ film thickness and in case of ECD it was Optima- 1 and length, ID and film thickness were the same. Nitrogen was used as carrier and make up gas in ECD and in FTD it was Helium. The instrument parameters for detecting organophosphorus insecticides and cypermethrin were as follows.

\begin{tabular}{lll}
\hline Instrument parameters & Organophosphorus insecticides & Cypermethrin \\
\hline $\begin{array}{l}\text { Machine } \\
\text { [Injection Port SPL] }\end{array}$ & GC-2010 & GC-2010 \\
Injector (Auto) & AOC $20 \mathrm{i}$ & AOC $20 \mathrm{i}$ \\
Injection Mode & Split & Split \\
Temperature & $250^{\circ} \mathrm{C}$ & $280^{\circ} \mathrm{C}$ \\
Carrier Gas & $\mathrm{He}$ & $\mathrm{N}_{2}$ \\
Flow Control Mode & Linear velocity & Linear velocity \\
Linear Velocity & $40.0 \mathrm{~cm} / \mathrm{sec}$ & $40.0 \mathrm{~cm} / \mathrm{sec}$ \\
Purge Flow & $3.0 \mathrm{ml} / \mathrm{min}$ & $3.0 \mathrm{ml} / \mathrm{min}$ \\
Split Ratio & 30.0 & 10.0 \\
Injection Volume & $1.0 \mu 1$ & $1.0 \mu 1$ \\
[Column Oven] & & \\
Column Oven Temperature Program: & & \\
Initial Temperature & $150^{\circ} \mathrm{C}$ & $160^{\circ} \mathrm{C}$ \\
Final Temperature & $220^{\circ} \mathrm{C}$ & $270^{\circ} \mathrm{C}$ \\
\hline
\end{tabular}




\begin{tabular}{lll}
$\begin{array}{l}\text { Equilibrium Time } \\
\text { Total Program Time } \\
\text { [Column Information] }\end{array}$ & $1.0 \mathrm{~min}$, Hold time: 2 & $1.0 \mathrm{~min}$, Hold time: 6 \\
Column Name & $10.0 \mathrm{~min}$ & $18.0 \mathrm{~min}$ \\
Column Length & ATTM-1 & Optima-1 \\
Film Thickness & $30.0 \mathrm{~m}$ & $30.0 \mathrm{~m}$ \\
Inner Diameter & $0.25 \mu \mathrm{m}$ & $0.25 \mu \mathrm{m}$ \\
[Detector Channel 1] & $0.25 \mathrm{~mm}$ & $0.25 \mathrm{~mm}$ \\
Detector & & \\
Temperature & FTD & ECD \\
Stop Time & $280^{\circ} \mathrm{C}$ & $300^{\circ} \mathrm{C}$ \\
Current & $10.0 \mathrm{~min}$ & $18.0 \mathrm{~min}$ \\
Makeup Gas & $1.0 \mathrm{pA}$ & $1.0 \mathrm{pA}$ \\
Makeup Flow & $\mathrm{He}$ & $\mathrm{N}_{2}$ \\
$\mathrm{H}_{2}$ Flow & $30.0 \mathrm{ml} / \mathrm{min}$ & $30.0 \mathrm{ml} / \mathrm{min}$ \\
Air Flow & $1.5 \mathrm{ml} / \mathrm{min}$ & - \\
\hline
\end{tabular}

Foregoing to the injection of the sample extract, standard solutions of different concentrations of five insecticides were prepared and injected with the above instrument parameters. The samples were calibrated (retention time, peak area etc.) against four pointed calibration curve of standard solution of concerned insecticide. Each peak was characterized by its retention time. Sample results were expressed in $\mathrm{mgkg}^{-1}$ automatically by the GC software which represented the concentration of the final volume injected. From this value the actual amount of insecticide residue present in the sample was determined by using the following formula.

Residue in sample $\left(\mathrm{mgkg}^{-1}\right)$

Conc. obtained in injected volume $\left(\mathrm{mgkg}^{-1}\right) \times$ Quantity of final volume $(\mathrm{L})$

Amount of sample taken $(\mathrm{kg})$

\section{Results}

The analytical results of the cauliflower samples for the detection of insecticide residue have been summarized in Table 1 to Table 3.

Table 1. Quantity of residue of different insecticides estimated from cauliflower in Gazipur location.

\begin{tabular}{|c|c|c|c|c|c|c|c|c|}
\hline \multirow[t]{2}{*}{ Locations } & \multirow{2}{*}{$\begin{array}{l}\text { Samples } \\
\text { analyzed } \\
\text { (no.) }\end{array}$} & \multirow[t]{2}{*}{ Frequencies } & \multicolumn{3}{|c|}{ Contaminated samples (no.) } & \multirow{2}{*}{$\begin{array}{l}\text { Detected } \\
\text { insecticide(s) }\end{array}$} & \multirow{2}{*}{$\begin{array}{l}\text { Residue level } \\
\left(\mathrm{mg} \mathrm{kg}^{-1}\right)\end{array}$} & \multirow{2}{*}{$\begin{array}{l}\text { MRL } \\
\left(\mathrm{mg} \mathrm{kg}^{-1}\right)^{*}\end{array}$} \\
\hline & & & Total & $\begin{array}{l}\text { Single } \\
\text { product }\end{array}$ & $\begin{array}{l}\text { Multi } \\
\text { product }\end{array}$ & & & \\
\hline \multirow[t]{6}{*}{ Gazipur } & 25 & 0 & 9 & & & Fenitrothion & 0.000 & 0.1 \\
\hline & & 2 & & 2 & & Quinalphos & $0.197,0.174$ & 0.2 \\
\hline & & 1 & & 1 & & Acephate & 1.181 & 0.5 \\
\hline & & 0 & & & & Malathion & 0.000 & 0.5 \\
\hline & & 0 & & & & Diazinon & 0.000 & 0.5 \\
\hline & & 6 & & 6 & & Cypermethrin & $\begin{array}{l}0.605, \quad 0.177, \\
0.139, \quad 0.054, \\
0.044,0.285\end{array}$ & 0.5 \\
\hline
\end{tabular}

*FAO/WHO Codex Alimentarius Commission, Codex Committee on Pesticide Residues (1993).

Out of 25 analyzed cauliflower samples of each location, the contaminated samples were almost same in Gazipur, Jessore and Rangpur location. In Gazipur 9 samples of cauliflower were contaminated with insecticides only in single product residue (Table 1). Malathion, diazinon and fenitrothion could not be detected in cauliflower. The detected quinalphos residue was remained below MRL but the detected residue levels of acephate was doubled the MRL. The residue of $0.605 \mathrm{mgkg}^{-1}$ of cypermethrin was above MRL only in one sample and the remaining 5 samples showed residue level below MRL. Multiple product residues were not found in the contaminated samples in this location. 
Table 2. Quantity of residue of different insecticides estimated from cauliflower in Jessore location.

\begin{tabular}{|c|c|c|c|c|c|c|c|c|}
\hline \multirow[t]{2}{*}{ Locations } & \multirow{2}{*}{$\begin{array}{l}\text { Samples } \\
\text { analyzed } \\
\text { (no.) } \\
\end{array}$} & \multirow[t]{2}{*}{ Frequencies } & \multicolumn{3}{|c|}{ Contaminated samples (no.) } & \multirow{2}{*}{$\begin{array}{l}\text { Detected } \\
\text { insecticide(s) }\end{array}$} & $\begin{array}{l}\text { Residue level } \\
\left(\mathrm{mg} \mathrm{kg}^{-1}\right)\end{array}$ & \multirow{2}{*}{$\begin{array}{l}\text { MRL } \\
\left(\mathrm{mg} \mathrm{kg}^{-1}\right)^{*}\end{array}$} \\
\hline & & & Total & $\begin{array}{l}\text { Single } \\
\text { product }\end{array}$ & $\begin{array}{l}\text { Multi } \\
\text { product }\end{array}$ & & & \\
\hline \multirow{8}{*}{ Jessore } & 25 & 1 & 10 & & 1 & Fenitrothion & 0.486 & 0.1 \\
\hline & & & & & & Quinalphos & 1.025 & 0.2 \\
\hline & & & & & & Acephate & 0.283 & 0.5 \\
\hline & & 2 & & & 1 & Quinalphos & 0.949 & 0.2 \\
\hline & & 1 & & & & Diazinon & 0.086 & 0.5 \\
\hline & & 2 & & & & Acephate & 0.229 & 0.5 \\
\hline & & 1 & & 1 & & Malathion & 0.214 & 0.5 \\
\hline & & 7 & & 7 & & Cypermethrin & $\begin{array}{ll}0.675, & 0.428, \\
0.265, & 0.208, \\
0.082, & 0.734, \\
0.059 & \\
\end{array}$ & 0.5 \\
\hline
\end{tabular}

*FAO/WHO Codex Alimentarius Commission, Codex Committee on Pesticide Residues (1993).

Both single and multiple products were detected in the cauliflower in Jessore region where 8 contaminated samples showed single insecticide in the residue. Malathion was detected but remained below MRL. Cypermethrin was detected in 7 samples with two samples above MRL and its rest of the samples were below MRL. Two samples of multiple insecticides detected in cauliflower revealed three insecticides. Fenitrothion, quinalphos and acephate were present in one multiple product sample where the first two (fenitrothion and quinalphos) insecticides were above MRL. The second sample of multiple products contained diazinon, acephate and quinalphos, latter being remained above MRL and diazinon and acephate at low residual level (Table 2).

Table 3. Quantity of residue of different insecticides estimated from cauliflower in Rangpur location.

\begin{tabular}{|c|c|c|c|c|c|c|c|c|}
\hline \multirow[t]{2}{*}{ Locations } & \multirow{2}{*}{$\begin{array}{l}\text { Samples } \\
\text { analyze } \\
\text { d (no.) } \\
\end{array}$} & \multirow[t]{2}{*}{ Frequencies } & \multicolumn{3}{|c|}{ Contaminated samples (no.) } & \multirow{2}{*}{$\begin{array}{l}\text { Detected } \\
\text { insecticide(s) }\end{array}$} & \multirow{2}{*}{$\begin{array}{l}\text { Residue level } \\
\left(\mathrm{mg} \mathrm{kg}^{-1}\right)\end{array}$} & \multirow{2}{*}{$\begin{array}{l}\text { MRL } \\
\left(\mathrm{mg} \mathrm{kg}^{-1}\right)^{*}\end{array}$} \\
\hline & & & Total & $\begin{array}{l}\text { Single } \\
\text { product }\end{array}$ & $\begin{array}{l}\text { Multi } \\
\text { product }\end{array}$ & & & \\
\hline \multirow{9}{*}{ Rangpur } & 25 & & 10 & & 1 & Fenitrothion & 0.179 & 0.1 \\
\hline & & & & & & Acephate & 0.861 & 0.5 \\
\hline & & & & & & Quinalphos & 0.397 & 0.2 \\
\hline & & 2 & & & 1 & Fenitrothion & 0.329 & 0.1 \\
\hline & & 2 & & & & Quinalphos & 0.962 & 0.2 \\
\hline & & 2 & & 1 & & Acephate & 0.462 & 0.5 \\
\hline & & 0 & & & & Malathion & 0.000 & 0.5 \\
\hline & & 1 & & 1 & & Diazinon & 0.450 & 0.5 \\
\hline & & 6 & & 6 & & Cypermethrin & $\begin{array}{l}0.961, \quad 0.867 \\
0.293, \quad 0.103 \\
0.086, \\
0.234\end{array}$ & 0.5 \\
\hline
\end{tabular}

\footnotetext{
* FAO/WHO Codex Alimentarius Commission, Codex Committee on Pesticide Residues (1993).
}

The contaminated samples of cauliflower from Rangpur location presented single product and multiple products residue (Table 3). In 8 single product samples, cypermethrin was detected in 6 samples (frequency 6). Two samples showed 0.961-0.867 $\mathrm{mgkg}^{-1}$ concentration of cypermethrin which were above MRL and rest of the samples were below MRL. Both acephate and diazinon were detected in single product sample, but were below MRL. Malathion was not detected in cauliflower in this location. There were 3 insecticides in one multiple product sample and two insecticides in other sample. All these insecticides remained above MRL in these two samples. 


\section{Discussion}

Among 75 analyzed samples of cauliflower collected from farmers' field of Jessore, Gazipur, and Rangpur revealed that $38.67 \%$ samples contaminated with six insecticides either singly or multiple product residues. In contaminated samples, $34.48 \%$ had residues which were above MRL. Most of the samples contained cypermethrin, quinalphos and fenitrothion residue in cauliflower. Diazinon was detected from cauliflower in both Rangpur and Jessore region but malathion was found only in Jessore location. The residue level of diazinon and malathion were below MRL. The residue levels of quinalphos, acephate, fenitrothion and cypermethrin were higher in cauliflower as compared to malathion and diazinon. Fenitrothion, diazinon and malathion residue were not found in cauliflower of Gazipur. Multiple products residue was found in both Rangpur and Jessore location. The presence of multiple product residues indicated that farmers applied more than one insecticide on cauliflower in all three locations. Some commercial farmers of vegetables especially in Jessore region have been spraying "Mixture of 3-5 insecticides" at every or every alternate day (Kabir et al. 1996; Rashid et al. 2003). This indiscriminate and irrational use of insecticides in the vegetables might cause the multiple residues of insecticides even at or above MRL level. Sing and Kalra (1996) found detectable level of residues of cypermethrin and fenvalerate up to 7 days of spraying of recommended dose in vegetables. Virgina and Bajet (1996) found residue of ogranophosphate insecticides (e.g. methomyl, triazophos, methyl parathion and diazinon) using rapid field kit from market basket samples of eggplant, tomato, cabbage and chinese peachy that exceeded MRL. El-Saeid and Selim (2013) found residues of organophosphorus, organochlorine, pyrethroid and carbamate from market vegetables (e.g. beans, eggplant, cauliflower, tomato, pepper, carrot, cucumber, squash, potato, onions and okra) that showed above the MRL in $15.89 \%$ of the total tested samples. The detected and most frequently found pesticide residues were permethrin (45 times) and endosulfan (34 times) followed by deltamethrin (27 times). Ahmed et al. (2013) found 38.67\% brinjal samples were contaminated with six insecticides (viz. acephate, fenitrotion, qunalphos, cypermethrin, diazinon and malathion), in which $44.835 \%$ samples had residue above MRL irrespective of single and multiple residues. The results of the present study agreed with the works of the above authors although the matrix and methods were different.

\section{Conclusions}

The samples of $13.33 \%$ of the total had residues above the MRL provided by the food and agricultural organization or world health organization. The residue level of quinalphos was found 5 times higher than MRL in Jessore and Rangpur, fenitrothion was 4 times higher in Jessore and acephate was double of the MRL in Gazipur location. The presence of higher levels of insecticides indicated that farmers might be used insecticide without maintaining pre harvest interval. So, the findings of this study are the need for a regular monitoring program for insecticide residues in environmental cauliflower samples and documented data are to be used as a reference point for future monitoring and taking preventive measures to minimize human health risks.

\section{Conflict of interest}

None to declare.

\section{References}

Ahmed MS, MA Sardar, MA Haque and KH Kabir, 2005. A survey on the pattern of insecticidal usage for the protection of brinjal (Solanum melongena) from the attack of insect pests in Jessore. Bangladesh J. Zool., 33: 57-63.

Ahmed MS, MA Sarder, MA Hoque, M Ahmad and KH Kabir, 2013. Determination of pyrethroid and organophosphorus insecticide residue in brinjal samples collected from some selected regions of Bangladesh. Bangladesh J. Entomol., 23: 39-51.

Anonymous, 1979. Methods of sampling for the official control of pesticide residues in and on fruits and vegetables. July 24, European Commission Directive 79/700/EEC, Vol. 11, 75 p.

Anonymous, 1993. Codex alimentarius, pesticide residues in food. Joint FAO/WHO Standards Program, FAO, Rome, Italy, Vol. 2, pp. 378-386.

Anonymous, 1996. Guidelines for the control of pesticide residues in foods. National Food Agency of Denmark (in Denish), $146 \mathrm{p}$.

Anonymous, 2001. Coordinated research on insecticide residue and resistance in major vegetables grown in Bangladesh. Report on Contact Research Project, BARC, BARI, Joydebpur, Gazipur, 102 p.

EL-Saeid MH and MT Selim, 2013. Multiresidue analysis of 86 pesticides using Gas Chromatography Mass Spectrometry: II-nonleafy vegetables. Journal of Chemistry, Volume 2013, Article ID 727149, 10 pages. 
Finney J, 1990. World crop protection prospects. Paper presented in Seventh International Congress of Pesticide Chemistry, Hamburg, Germany, August 5-10, 1990.

MacIntyre AN, N Allison and DR Penman, 1989. Pesticides: Issues and options for New Zealand. Ministry of the Environment, Wellington, New Zealand, 7: 29.

Rashid MA, SN Alam, FMA Rouf and NS Taleker, 2003. Socio- economic parameters of eggplant pest control in Jessore district of Bangladesh. AVRDC Technical Bull. 29: 1-54.

Riley D and S Sparks, 2008. Common insects affecting cabbage and related cole crops. The University of Georgia College of Agriculture and Environmental Sciences (http:// www.ent.uga.edu/veg/cole crops. htm).

Singh IP and RL Kalra, 1996. Persistence and degradation of Fenvalerate on brinjal. Indian J. Ent., 58: 27-31.

Virgina RO and CM Bajet, 1996. Pesticides in the Philippine environment. In: Proceedings. Anniversary and Annual Scientific Meeting, (Dizon, T. D., Eusebio J. E., Duenas J. N., Palis F. V. and Mabbayad M. O. eds.). Pest Management Council of the Philippine, Davao City, pp. 61-77. 